\title{
A Developmental Shift from GABAergic to Glycinergic Transmission in the Central Auditory System
}

\author{
Vibhakar C. Kotak, ${ }^{1}$ Sailaja Korada, ${ }^{3}$ Ilsa R. Schwartz, ${ }^{3}$ and Dan H. Sanes ${ }^{1,2}$ \\ ${ }^{1}$ Center for Neural Science and 2Department of Biology, New York University, New York, New York 10003, and \\ ${ }^{3}$ Department of Surgery/Otolaryngology, Yale University School of Medicine, New Haven, Connecticut 06520-8041
}

\begin{abstract}
GABAergic and glycinergic circuits are found throughout the auditory brainstem, and it is generally assumed that transmitter phenotype is established early in development. The present study documents a profound transition from GABAergic to glycinergic transmission in the gerbil lateral superior olive (LSO) during the first 2 postnatal weeks. Whole-cell voltage-clamp recordings were obtained from LSO neurons in a brain slice preparation, and IPSCs were evoked by electrical stimulation of the medial nucleus of the trapezoid body (MNTB), a known glycinergic projection in adult animals. GABAergic and glycinergic components were identified by blocking transmission with bicuculline and strychnine (SN), respectively. In the medial limb of LSO, there was a dramatic change in the GABAergic IPSC component, decreasing from $78 \%$ at postnatal day 3 (P3)-P5 to $12 \%$ at P12-P16. There was an equal and opposite increase in the glycinergic component during this same period. Direct application of GABA also elicited significantly larger amplitude and longer duration responses in P3-P5 neurons compared
\end{abstract}

In contrast to the literature on the developmental plasticity of excitatory synapses, little is known about activity-dependent mechanisms at inhibitory terminals. In the adult nervous system, GABA and glycine are each known to hyperpolarize the postsynaptic membrane by gating chloride channels (Bormann et al., 1987). However, during early development, GABA or glycine often produces a membrane depolarization that is accompanied by an influx of calcium (Connor et al., 1987; Ben-Ari et al., 1989; Ito and Cherubini, 1991; Obrietan and Van den Pol, 1995; Lo et al., 1998). In the developing lateral superior olive (LSO), a binaural nucleus in the ventral auditory brain stem, inhibitory synapses can depolarize cells directly (Kandler and Friauf, 1995) or elicit a hyperpolarization followed by a rebound depolarization (Sanes, 1993). Thus, the transient depolarizing influence of inhibitory terminals could allow them to use calcium-dependent mechanisms thought to play a role in the stabilization or elimination of excitatory terminals (Connold et al., 1986; Cash et al., 1996).

Inhibitory afferents to the LSO project from the medial nucleus of the trapezoid body (MNTB), a glycinergic nucleus that is activated by sound to the contralateral ear (Guinan et al., 1972a,b;

\footnotetext{
Received Jan. 15, 1998; revised March 23, 1998; accepted March 26, 1998.

This work was supported by National Institutes of Health Grants DC00540 (D.H.S.) and DC00132 (I.R.S.).

Correspondence should be addressed to Dan H. Sanes, Center for Neural Science, 4 Washington Place, New York University, New York, NY 10003.

Copyright (C) 1998 Society for Neuroscience $0270-6474 / 98 / 184646-10 \$ 05.00 / 0$
}

with glycine-evoked responses. In contrast, MNTB-evoked IPSCs in lateral limb neurons were more sensitive to SN throughout development. Consistent with the electrophysiological observations, there was a reduction in staining for the $\beta_{2,3}-\mathrm{GABA}_{\mathrm{A}}$ receptor subunit from $\mathrm{P} 4$ to $\mathrm{P} 14$, whereas staining for the glycine receptor-associated protein gephyrin increased. Brief exposure to baclofen depressed transmission at excitatory and inhibitory synapses for $\sim 15 \mathrm{~min}$, suggesting a GABA $B^{-}$ mediated metabotropic signal. Collectively, these data demonstrate a striking switch from GABAergic to glycinergic transmission during postnatal development. Although GABA and glycine elicit similar postsynaptic ionotropic responses, our results raise the possibility that GABAergic transmission in neonates may play a developmental role distinct from that of glycine.

Key words: $G A B A_{A}$; glycine; inhibition; $G A B A_{B}$; development; gerbil; lateral superior olive
Moore and Caspary, 1983; Spangler et al., 1985; Wenthold et al., 1987, 1990; Zook and DiCaprio, 1988; Sanes and Siverls, 1991; Schwartz, 1992). Anatomically, LSO is innervated by terminals that contain flattened or pleomorphic vesicles that stain positively with both GABA and glycine antibodies (Helfert et al., 1989, 1992). In adult animals, LSO neurons encode interaural level differences by integrating excitatory potentials driven by the ipsilateral ear and inhibitory potentials driven by the contralateral ear (Boudreau and Tsuchitani, 1970; Caird and Klinke, 1983; Harnischfeger et al., 1985; Sanes and Rubel, 1988).

The inhibitory terminals from MNTB appear to be dynamic during early development, displaying a physical reduction in their arbor size and a reduction in the number of functional inhibitory afferents per postsynaptic neuron (Sanes and Siverls, 1991; Sanes, 1993). Furthermore, when inhibitory transmission is disrupted during development, both the morphology and physiology of LSO neurons are affected (Sanes et al., 1992; Sanes and Takács, 1993; Aponte et al., 1996; Kotak and Sanes, 1996; Sanes and Hafidi, 1996). For example, denervation of the glycinergic afferents to LSO or strychnine rearing result in the upregulation of functional NMDA receptors, thus enhancing excitatory transmission (Kotak and Sanes, 1996). Therefore, we are interested in inhibitory synaptic mechanisms that might contribute to presynaptic and postsynaptic maturation. In the present report, we present physiological and anatomical evidence for a major transition from GABAergic to glycinergic inhibitory transmission during early development and provide evidence that early GABAergic transmission may activate metabotropic receptors. 


\section{MATERIALS AND METHODS}

Brain slice physiology. Postnatal gerbils (Meriones unguiculatus) at postnatal day 3 (P3)-P16 were used to generate brain slices through the LSO, MNTB, and ipsilateral cochlear nucleus afferents (Sanes, 1993). Transverse vibratome sections of $300 \mu \mathrm{m}$ were cut in cold $\left(\sim 8^{\circ} \mathrm{C}\right)$ oxygenated artificial CSF (ACSF), preincubated at room temperature for $2 \mathrm{hr}$ in a holding chamber, and transferred to the recording chamber where ACSF was superfused at $7 \mathrm{ml} / \mathrm{min}$ at room temperature. The ACSF contained (in mM): $123 \mathrm{NaCl}, 4 \mathrm{KCl}, 1.2 \mathrm{KH}_{2} \mathrm{PO}_{4}, 1.3 \mathrm{MgSO}_{4}, 28 \mathrm{NaHCO}_{3}, 15$

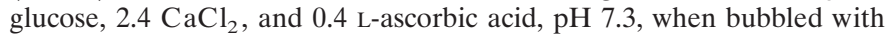
$95 \% \mathrm{O}_{2}$ and $5 \% \mathrm{CO}_{2}$.

Recording electrodes were fabricated from 1.5 -mm-outer diameter borosylicate glass microcapillaries, and they had a resistance of 4-6 M $\Omega$. For current-clamp recordings, the composition of the internal pipette solution was (in mM): 130 potassium gluconate, 0.6 EGTA, 10 HEPES, 2 $\mathrm{MgCl}_{2}, 5 \mathrm{KCl}, 2 \mathrm{ATP}$, and $0.3 \mathrm{GTP}, \mathrm{pH}$ 7.2. Whole-cell voltage-clamp recordings were obtained with pipettes containing (in $\mathrm{mM}$ ): 127.5 cesium gluconate, 0.6 EGTA, $10 \mathrm{HEPES}, 2 \mathrm{MgCl}_{2}, 5 \mathrm{KCl}$, $2 \mathrm{ATP}, 0.3 \mathrm{GTP}$, and 5 QX-314, $\mathrm{pH}$ 7.2. The resting potential was checked immediately after breaking the cell membrane, and neurons with a resting potential of -40 $\mathrm{mV}$ or better were used in this analysis. Custom-designed software running on a 486 personal computer platform was used for programmed stimulus delivery, data acquisition, and analysis (Sanes, 1993). Bipolar stimulating electrodes were placed on the MNTB and the afferent pathway from the ipsilateral cochlear nucleus at the lateral edge of LSO. Incremental voltage pulses $(200 \mu \mathrm{sec})$ were delivered to each set of afferents at $0.5 \mathrm{~Hz}$, and the maximum amplitude IPSC was determined. The data were divided into three age ranges: P3-P5, P8-P11, and P12-P16.

The IPSCs were recorded at holding potentials of $-20-0 \mathrm{mV}$ in the presence of 6-cyano-7-nitroquinoxaline-2,3-dione (CNQX; $20 \mu \mathrm{M})$ and $\mathrm{D}-(O)$-2-amino-5-phosphonopentanoic acid (AP-5; $50 \mu \mathrm{M} ; n=35)(\mathrm{Re}-$ search Biochemicals, Natick, MA), or kynurenic acid (KYN; $5 \mathrm{~mm} ; n=$ 36). The glycinergic IPSC component was blocked with strychnine (SN; $2 \mu \mathrm{M}$; Sigma, St. Louis, MO), and the GABAergic IPSC component was blocked with bicuculline (BIC; $10 \mu \mathrm{M}$; Sigma). For GABA (5 mM; $15 \mathrm{sec})$ or glycine $(5 \mathrm{~mm} ; 15 \mathrm{sec})$ exposure, slices were first incubated in KYN. To avoid long-lasting alterations in intracellular environment, only a single agonist dose was tested per slice. Voltage-clamp $(n=4)$ and current-clamp $(n=4)$ recordings were also performed to examine the effects of a $\mathrm{GABA}_{\mathrm{B}}$ agonist, baclofen $(50 \mu \mathrm{M})$, on synaptic function and membrane properties. The data include whole-cell recordings from 101 LSO neurons from 87 brain slices.

Immunocytochemistry. Gerbils at P4 $(n=3)$ and P14 $(n=3)$ were anesthetized with sodium pentobarbital and perfused transcardially with cold saline nitrite solution $(0.9 \%$ sodium chloride and $0.1 \%$ sodium nitrite) followed by cold fixative (4\% paraformaldehyde and $0.1 \%$ glutaraldehyde) in $0.12 \mathrm{M}$ PBS, $\mathrm{pH}$ 7.4. After 30-60 min on ice, brains were removed and immersed overnight in cold fixative. Brains were then washed in PBS and transferred to $30 \%$ sucrose in buffer overnight. The brains were then placed in OCT mounting compound (Miles, Elkhart, IN) and frozen in ethanol over dry ice. Serial cryostat sections $(30 \mu \mathrm{m})$ of the brainstem cut in the coronal plane were used for immunohistochemical staining with monoclonal antibodies directed against the glycine receptor-associated protein gephyrin (Boehringer Mannheim, Indianapolis, IN) and the $\mathrm{GABA}_{\mathrm{A}}$ receptor $\beta_{2,3}$ subunit (Boehringer Mannheim). Sections were washed in buffer and treated with $10 \%$ normal horse serum with $2 \%$ bovine serum albumin (BSA) in PBS for $1 \mathrm{hr}$ before they were incubated overnight at room temperature on a shaker in primary antiserum $\left(1 \mu \mathrm{g} / \mathrm{ml} \mathrm{GABA}_{\mathrm{A}}\right.$ or $0.5 \mu \mathrm{g} / \mathrm{ml}$ gephyrin). Antibodies were diluted in a PBS solution containing $1 \%$ horse serum and $2 \%$ BSA. On the following day the sections were washed three times for $20 \mathrm{~min}$ each in PBS, incubated in biotinylated anti-mouse $\operatorname{IgG}$ for $1 \mathrm{hr}$, and washed again for three times for $20 \mathrm{~min}$ each in PBS. Sections were then treated with an avidin-biotin-peroxidase complex (Vectastain ABC mouse Elite kit; Vector Laboratories, Burlingame, CA). The reaction was visualized using a solution containing $0.0125 \%$ diaminobenzidine (DAB), $0.0005 \%$ hydrogen peroxide, and $0.064 \%$ nickel chloride. Omission of the primary antiserum served as a control. Sections were mounted on $0.5 \%$ Elmer's glue-coated slides, dehydrated, coverslipped, and photographed with a Nikon Biophot microscope.

\section{MEDIAL LIMB \\ MNTB stimulation}

$\underline{\mathrm{P}} 4$
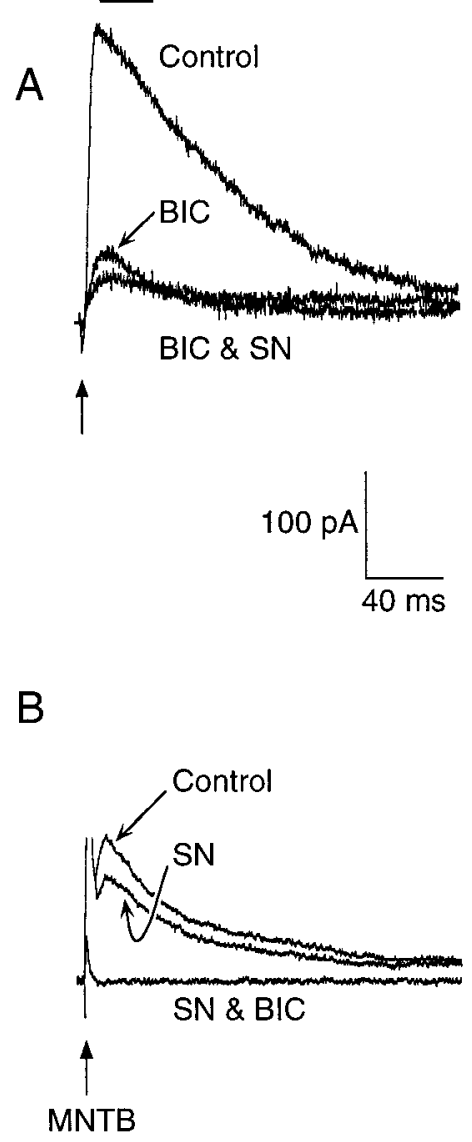

$\underline{P 14}$
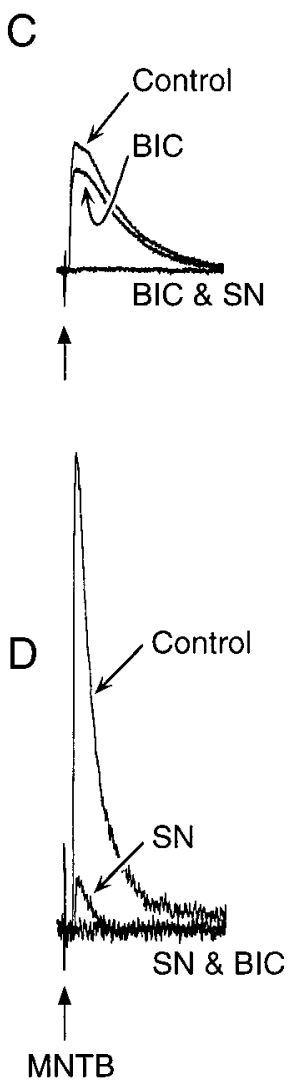

Figure 1. For medial limb neurons, MNTB-evoked IPSCs are primarily BIC-sensitive at P4 (left) and SN-sensitive at P14 (right). $A$, In a P4 medial limb neuron, a major component of MNTB-evoked maximum IPSC was reduced by BIC $(10 \mu \mathrm{M})$, whereas addition of SN $(2 \mu \mathrm{M})$ marginally decreased the remaining IPSC $(B I C \& S N)$. A small current remained in the presence of BIC and SN. $B$, In a second $\mathrm{P} 4$ neuron, initial application of SN marginally decreased the IPSC, whereas addition of BIC ( $S N$ \& $B I C$ ) eliminated the major IPSC component. $C$, In a P14 LSO neuron, BIC reduced the IPSC only slightly, whereas addition of SN $(B I C \& S N)$ eliminated the major component. $D$, In a second P14 LSO neuron, initial application of SN decreased the major IPSC component, whereas addition of BIC $(S N \& B I C)$ eliminated the small remaining IPSC. Holding potential was $0 \mathrm{mV}$. MNTB stimulus is indicated by arrows.

\section{RESULTS}

Several anatomical findings indicate that the medial (highfrequency) and lateral (low-frequency) limbs of the gerbil LSO differ from one another, including the density of glycine receptors and MNTB afferents (Sanes et al., 1987; Sanes and Siverls, 1991). Therefore, we have analyzed the electrophysiological data obtained from medial and lateral limb neurons separately.

\section{Inhibitory currents in the medial limb}

Ipsilaterally and MNTB-evoked IPSCs were recorded in 44 of 45 medial limb neurons. Figure $1 A$ shows a $\mathrm{P} 4$ neuron in which 10 $\mu \mathrm{M}$ BIC reduced the major IPSC component, whereas the remainder was almost eliminated by $2 \mu \mathrm{M}$ SN. An identical result was obtained when the sequence of antagonist exposure was reversed in a second neuron (Fig. $1 B$ ). In contrast, BIC marginally decreased IPSC amplitude in a P14 neuron, whereas SN 


\section{MEDIAL LIMB \\ MNTB stimulation}
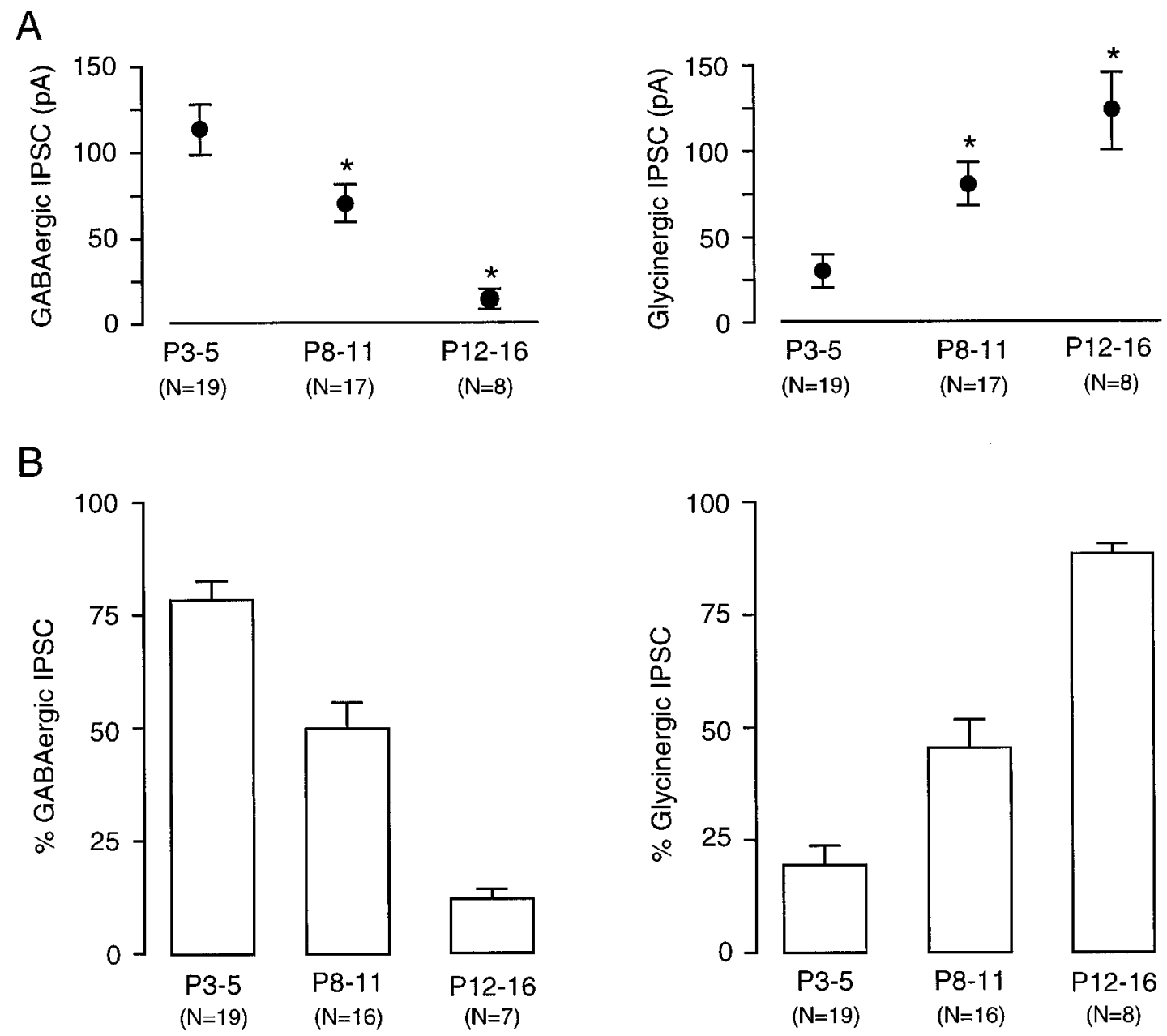

Figure 2. Summary of MNTB-evoked inhibitory current pharmacology in the medial limb. $A$, The BIC-sensitive (GABAergic) IPSC component shows a declining trend from P3-P5 through P12-P16 (left), and there is a concomitant increase in the SN-sensitive (Glycinergic) IPSC components (right). These trends were highly significant (asterisk) (ANOVA, $F=8.8 ; p<0.0006)(t$ test comparisons for GABAergic currents: $\mathrm{P} 3-\mathrm{P} 5$ vs P8-P11, $t=2$; df $=$ $33 ; p<0.015 ; \mathrm{P} 8-\mathrm{P} 11$ vs P12-P16, $t=2.8 ; \mathrm{df}=22 ; p<0.001 ; \mathrm{P} 3-\mathrm{P} 5$ vs $\mathrm{P} 12-\mathrm{P} 16, t=2.7 ; \mathrm{df}=25 ; p<0.001)(t$ test comparisons for glycinergic currents: P3-P5 vs P8-P11, $t=2.7$; df $=33 ; p<0.002 ; \mathrm{P} 8-\mathrm{P} 11$ vs P12-P16, $t=2 ; \mathrm{df}=22 ; p<0.04 ; \mathrm{P} 3-\mathrm{P} 5$ vs P12-P16, $t=2.7$; df $=25 ; p<0.0001)$. $B$, Normalized percent of BIC-sensitive (GABAergic) IPSC component (left) predominated in early postnatal life (P3-P5) was present at an $\sim 50 \%$ level at P8-P11, and was present at an $\sim 10 \%$ in older animals (P12-P16). There was an almost equal and opposite increase in the SN-sensitive (Glycinergic) IPSC component recorded from the same group of neurons. Mean $\pm \mathrm{SEM} ; n$ values are in parentheses.

eliminated the remaining component (Fig. 1C). Once again, a similar trend was observed when SN was used first, followed by BIC in a separate neuron (Fig. $1 D)$. In P4 $(n=2)$ and P14 $(n=$ 2) neurons, reversal of the BIC effect was followed by SN application in the same neuron, producing complementary reduction of the IPSCs, which is consistent with the recordings shown in Figure 1. A summary of MNTB-evoked IPSC amplitudes is shown in Figure 2. The decreasing contribution of GABAergic transmission with age is evident when the data are plotted as the amplitude of pharmacologically isolated IPSCs (Fig. $2 A$ ) or as a percent of the total IPSC amplitude (Fig. $2 B$ ). The total calculated conductance for MNTB-evoked IPSCs did not vary significantly with age $(5 \pm 1.1 \mathrm{nS}$ at P3-P5, $7.2 \pm 1.1 \mathrm{nS}$ at P8-P11, and $4.9 \pm 2.1 \mathrm{nS}$ at P12-P16, mean $\pm \mathrm{SEM}$; ANOVA, $p>0.3$, df $=$ 33). In some neurons, a small amplitude current persisted after exposure to both antagonists (Fig. $1 A$ ). This small remaining synaptic current (not blocked by BIC and SN) generally reversed at a holding potential more negative than $-30 \mathrm{mV}(n=3)$. The percentage reductions in ipsilaterally evoked IPSCs by BIC or SN were similar to those observed for MNTB stimulation at all ages (data not shown).

An important question that arises is why we failed to observe significant GABAergic inhibition in previous current-clamp studies (Sanes and Hafidi, 1996; Kotak and Sanes, 1996). To assess possible "masking" of GABAergic synaptic potentials, we performed additional current-clamp recordings while sequentially applying pharmacological agents ( $n=8,4$ each at P4 and P10). As shown for two different neurons in Figure 3, SN application eliminated the IPSPs but also unmasked contralateral EPSPs (Fig. $3 A$ ) or mixed responses (Fig. 3B). Addition of KYN (5 mM) abolished any excitatory potentials and revealed $\mathrm{SN}$-insensitive IPSPs. These IPSPs were then blocked by BIC. 


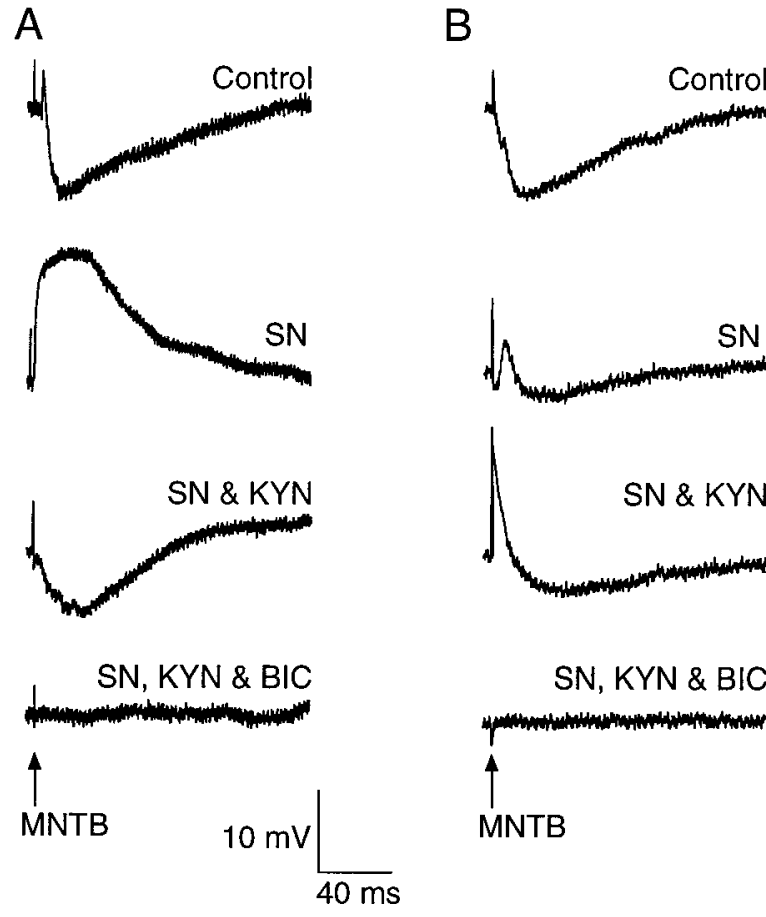

Figure 3. Current-clamp recordings from medial limb neurons show that MNTB-evoked excitation can conceal GABAergic inhibition. $A$, In a P3 neuron, MNTB stimulation evokes a sizable synaptic response that is primarily hyperpolarizing before drug exposure (Control). When SN (5 $\mu \mathrm{M})$ was bath-applied, a large EPSP was evoked by MNTB stimulation $(S N)$. The addition of KYN (5 mM) eliminated the EPSP and revealed an underlying IPSP $(S N \& K Y N)$. Finally, the addition of BIC $(30 \mu \mathrm{M})$ abolished the IPSP ( $S N, K Y N \& B I C)$. Resting potential was $-45 \mathrm{mV}$. B, In a P10 neuron, MNTB stimulation evokes a large hyperpolarizing potential before drug application (Control). Application of SN $(5 \mu \mathrm{M})$ abolishes the major IPSP, leaving a small depolarizing potential $(S N)$. Superfusion of KYN (5 mM) reveals a small IPSP $(S N \& K Y N)$. Finally, this IPSP is blocked with BIC $(30 \mu \mathrm{M})(S N, K Y N \& B I C)$. Resting potential was $-52 \mathrm{mV}$.

To assess the relative postsynaptic sensitivity to GABA or glycine, P3-P5 medial limb neurons were exposed to either of the two transmitters ( $5 \mathrm{~mm} ; 15 \mathrm{sec})$, and the holding current was monitored at a holding potential of $-90 \mathrm{mV}$. For this experiment, we restricted analyses to the early ages when GABAergic transmission predominated (P3-P5). Figure $4 A$ shows representative currents obtained from each agonist and illustrates the greater response to GABA. A summary of the data (Fig. 4B) indicates that GABA induced larger-amplitude and longer-duration currents than those elicited by glycine. In two P4 lateral limb neurons that did not display IPSCs, GABA application also produced sizable responses (321 and $340 \mathrm{pA}, 110$ and $140 \mathrm{sec}$ ).

In voltage-clamp recordings, the reversal potential of MNTBevoked IPSCs were relatively depolarized in P3-P5 neurons and gradually shifted close to the calculated $E_{\mathrm{Cl}}$ with increasing postnatal age (Fig. 5). An identical observation was made for ipsilaterally evoked IPSCs (data not shown). When $E_{\text {IPSC }}$ was compared in neurons from P7 animals before and after BIC application, it remained unchanged (control $E_{\mathrm{IPSC}}=-41 \pm 1.7$ $\mathrm{mV} ; E_{\text {IPSC }}$ after BIC treatment $=-40 \pm 1.9 \mathrm{mV}$, mean $\pm \mathrm{SEM}$; $n=3$ ). However, it should be noted that hyperpolarizing IPSPs were observed in current-clamp recordings, even at P3-P5.

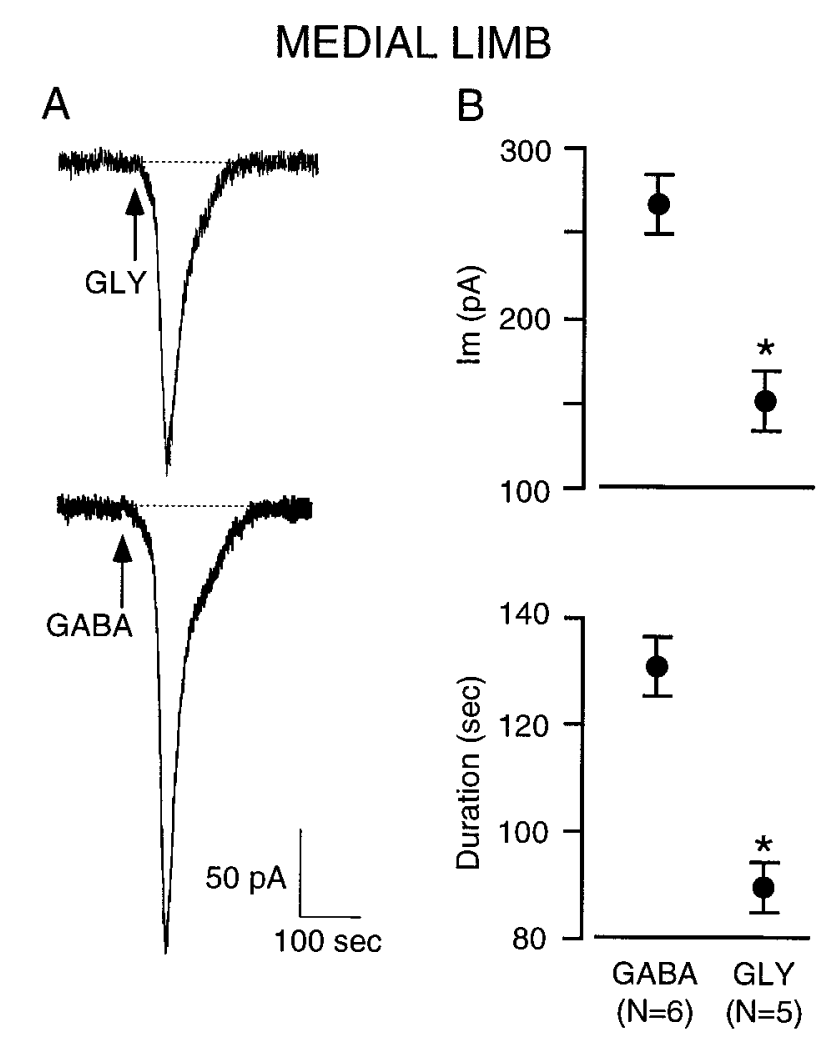

Figure 4. GABA elicits a greater response than glycine in P3-P5 medial limb neurons. $A$, In a $\mathrm{P} 4$ neuron, a $15 \mathrm{sec}$ bath application of glycine (5 mM; arrow, $G L Y$ ) elicited an inward current that returned to baseline after $\sim 2$ min. In a P4 neuron from another slice from the same animal, a $15 \mathrm{sec}$ bath application of GABA (5 mM; arrow, GABA) elicited a larger-amplitude and longer-lasting current $(\sim 3 \mathrm{~min})$. Recordings were made in the presence of KYN (5 mM) at a holding potential of $-90 \mathrm{mV}$. $B$, The graphs show that in P3-P5 LSO neurons, GABA elicited a significantly (asterisk) greater change in holding current (top), and this lasted for a significantly (asterisk) longer duration (bottom). (Amplitude: GABA vs glycine, $t=3.2 ; \mathrm{df}=9 ; p<002$; duration: GABA vs glycine, $t=3.2 ;$ df $=9 ; p<0.001)$.

\section{Inhibitory currents in the lateral limb}

MNTB or ipsilateral stimulation elicited IPSCs in 22 of 26 LSO lateral limb neurons, although all neurons displayed bilateral excitatory synaptic currents. Although BIC decreased IPSC amplitude in P3-P5 and P12-P16 neurons (ipsilateral, 20 of 26; MNTB, 22 of 26 neurons), the addition of SN nearly eliminated the major IPSC component at both ages (Fig. 6A). In three P4 animals, recordings were obtained from medial and lateral limb neurons in the same slice. Although BIC eliminated most of the IPSC in the medial limb neuron, it only blocked a minor fraction of the IPSC recorded in the lateral limb. Figure $6 B$ presents a summary of the GABAergic and glycinergic synaptic components recorded in lateral limb neurons and illustrates that sensitivity to $\mathrm{BIC}$ and SN did not change with age. BIC reduced the MNTBevoked IPSCs by $24 \pm 6 \%$ at P3-P5 and $15 \pm 5 \%$ at P12-P16 $(t=-0.9 ; \mathrm{df}=21 ; p>0.3)$. A similar trend was observed for ipsilaterally evoked IPSCs (data not shown). Lateral limb neurons also differed from medial limb neurons in that they did not exhibit depolarized IPSC reversal potentials in young animals. At P3-P5, MNTB-evoked $E_{\text {IPSC }}$ was $-48 \pm 3.1 \mathrm{mV}$ for lateral limb neurons compared with $-31 \pm 2.2 \mathrm{mV}$ for medial limb neurons $(t=4.5 ; \mathrm{df}=31 ; p<0.0001)$. 


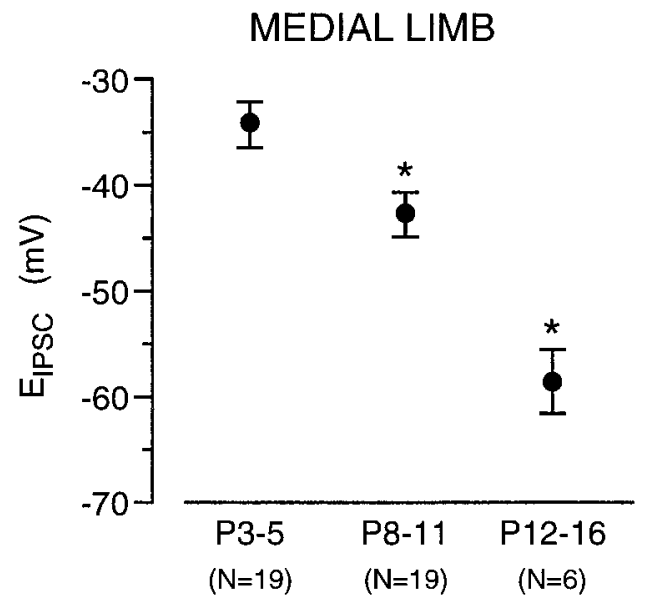

Figure 5. In medial limb neurons, the IPSC reversal potential shifts toward a more negative value with age. The plot shows that there was a progressive change in MNTB-evoked $E_{\text {IPSC }}$ from approximately $-35 \mathrm{mV}$ in P3-P5 LSO neurons to approximately $-60 \mathrm{mV}$ in P12-P16 neurons. The $E_{\text {IPSC }}$ value for the P8-P11 group was intermediate. This change was highly significant (asterisk) (ANOVA, $F=26.7 ; p<0.0001$; pairwise comparisons: $\mathrm{P} 3-\mathrm{P} 5$ vs $\mathrm{P} 8-\mathrm{P} 11, t=2.7 ; \mathrm{df}=36 ; p<0.001 ; \mathrm{P} 8-\mathrm{P} 11$ vs $\mathrm{P} 12-\mathrm{P} 16, t=2.8$; df $=24 ; p<0.001$; $\mathrm{P} 3-\mathrm{P} 5$ vs $\mathrm{P} 12-\mathrm{P} 16, t=2.8 ; \mathrm{df}=23$; $p<0.001)$. Mean $\pm \mathrm{SEM} ; n$ values are in parentheses.

\section{Effect of baclofen}

Because GABAergic transmission appeared to be prominent in neonatal animals, we examined whether a $\mathrm{GABA}_{\mathrm{B}}$ mechanism was present in P5-P6 medial limb neurons. Baclofen elicited a reversible (10-15 $\mathrm{min})$ decrease in ipsilaterally evoked EPSP amplitude $(\sim 80 \%)$ and in MNTB-evoked IPSP amplitude $(\sim 50 \%)$. In two neurons there was a $20 \%$ decrease in input resistance, although no change was noted in membrane potential, input resistance, or spike threshold in the other two neurons (Fig. 7). In two voltage-clamp recordings, a similar baclofen-evoked reduction in EPSCs and IPSCs was observed.

\section{Immunocytochemical localization of $\mathrm{GABA}_{\mathrm{A}}$ and glycine receptors}

At P4, the LSO was stained relatively intensely with $\mathrm{GABA}_{\mathrm{A}}$ receptor antibody and appeared darker compared with adjacent areas (Fig. 8A). There was no apparent difference in the staining pattern between the medial and lateral limbs. At higher magnification, the neurons showed punctate staining on the somatic periphery and darkly stained neuropil, although a few cells had patchy staining throughout the soma (Fig. 9A). At P14, there was a considerable reduction in the intensity of staining within the LSO (Fig. 8C) compared with the staining at P4. At higher magnification, there was a clear reduction in the neuropil staining, although a few cells with intense staining were observed occasionally (Fig. 9C).

In contrast, gephyrin staining at $\mathrm{P} 4$ was much less intense in the medial limb of LSO (Figs. $8 B, 9 B$ ) compared with $\mathrm{GABA}_{\mathrm{A}}$ receptor staining. At $\mathrm{P} 14$, there was a dramatic increase in the intensity of staining in the medial limb (Figs. 8D, 9D) compared with P4. Although the intensity of somatic staining remained at the same level in both medial and lateral limbs, neuropil of the medial limb was stained darker compared with that of the lateral limb. This feature made the medial limb appear more darkly stained than the lateral limb at P14 (Fig. 8D). A large number of positively stained cells were seen in the lateral limb of LSO at P4, and a few faintly stained cells could be identified in the medial

\section{LATERAL LIMB \\ MNTB stimulation}
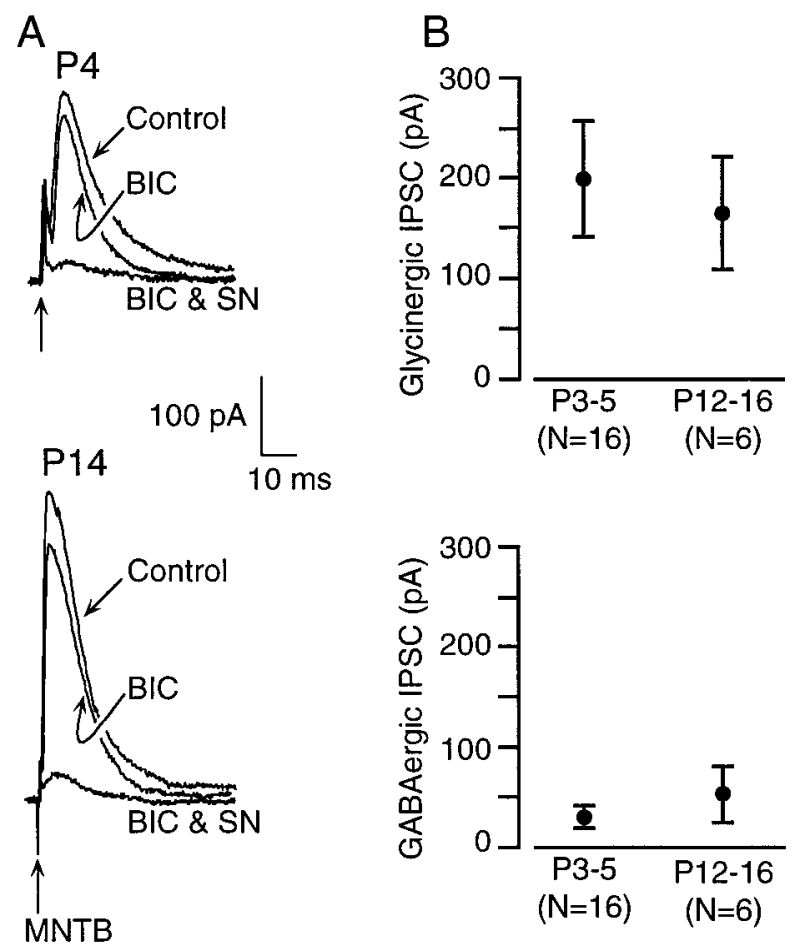

Figure 6. In the LSO lateral limb, MNTB-evoked inhibitory currents remain primarily glycinergic through the first 2 postnatal weeks. $A, \mathrm{~A} \mathrm{P} 4$ neuron displayed low sensitivity to BIC, but the addition of SN $(B I C$ \& $S N$ ) abolished the major IPSC component. In a P14 neuron, BIC application reduced the IPSC only slightly, whereas addition of SN nearly abolished the major IPSC component $(B I C \& S N)$. For comparison with medial limb responses, see Figure 1. B, Plots showing the amplitudes of SN-sensitive (Glycinergic) and BIC-sensitive (GABAergic) IPSC components at P3-P5 and P12-P16. There was no significant difference between the two age groups. (Glycinergic: P3-P5 vs P12-P16, $t=2.08$; $\mathrm{df}=20 ; p>$ 0.7; GABAergic: P3-P5 vs P12-P16, $t=2.08$; df $=20 ; p>0.4)$. Mean \pm SEM; $n$ values are in parentheses.

limb. From the morphology they did not appear to be the principal cells (Fig. 9B). Much of this somatic gephyrin staining may be located intracellularly. A striking feature was the gephyrinpositive axons running within the nucleus (Fig. 9B) that were not apparent in P14 animals.

\section{DISCUSSION}

The major finding in this study is a switch from GABAergic to glycinergic transmission in the medial limb of the gerbil LSO during the first 2 postnatal weeks. This change could arise from an alteration of the MNTB neurotransmitter and/or the LSO receptor. Alternatively, transient GABAergic projections to LSO may be activated by stimuli delivered to the MNTB region (e.g., axons of passage) and the ipsilateral pathway. Below, we argue in favor of a transition of existing projections.

\section{Development of glycinergic transmission in the medial limb}

There is a striking developmental transformation from GABAergic to glycinergic transmission in the medial limb of the LSO (Figs. 1,2). This conclusion is based on the fact that $\sim 80 \%$ of ipsilaterally and MNTB-evoked IPSCs were blocked by BIC in 
MEDIAL LIMB

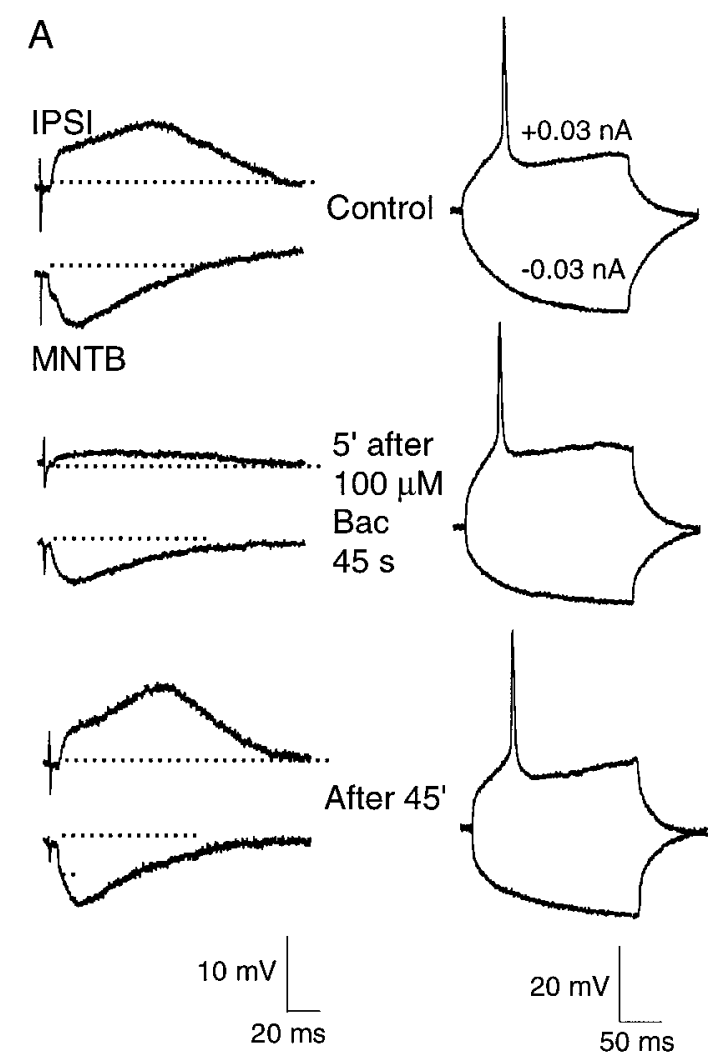

B

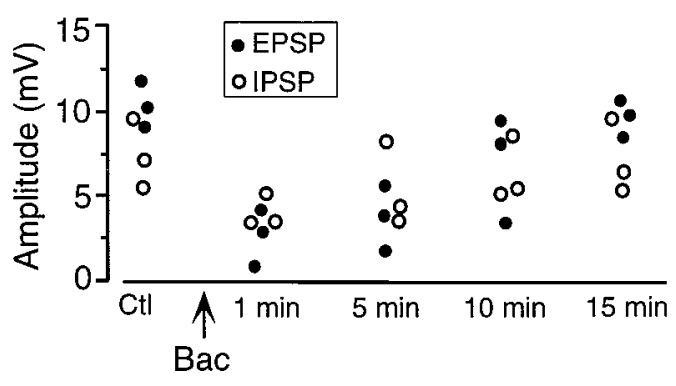

Figure 7. Baclofen causes a long-lasting depression of synaptic transmission in the LSO. $A$, In current-clamp recording from a P6 medial limb neuron, subthreshold ipsilateral stimulation (IPSI) and MNTB stimulation elicited sizable EPSPs and IPSPs, respectively (top left). Responses of this neuron to a depolarizing and hyperpolarizing current injection are also shown (right). Five minutes after a $45 \mathrm{sec}$ exposure to baclofen (Bac; $100 \mu \mathrm{M}$ ), both the EPSP and IPSP remained depressed (left middle), whereas the current-evoked responses were unchanged (right middle). Full recovery was seen $\sim 45$ min after the initial exposure period. $B$, Plot showing replication of this experiment but with only $10 \mathrm{sec}$ baclofen exposure periods $(B a c ; 100 \mu \mathrm{M})$ in three P6 medial limb LSO neurons. Control EPSPs (filled circles) and IPSPs (open circles) were depressed by $\sim 50 \%$ or more $1 \mathrm{~min}$ after the brief baclofen exposure $(B a c)$. The evoked synaptic potential amplitudes reached nearly complete recovery by $\sim 15 \mathrm{~min}$.

P3-P5 animals, whereas the IPSCs became primarily SNsensitive after P11. Furthermore, GABA-evoked currents were larger and of longer duration in P4 neurons compared with glycine-evoked currents (Fig. 4). Finally, we observed a comparable change in staining with antibodies to $\mathrm{GABA}_{\mathrm{A}}$ receptor and gephyrin (Figs. 8, 9). Staining for the $\beta_{2,3} \mathrm{GABA}_{\mathrm{A}}$ receptor subunit was intense throughout the LSO at P4 but declined by P14. A similar finding was reported previously in the rat (Fritschy et al., 1994). In contrast, gephyrin staining was low at P4, particularly in the LSO medial limb, but increased by P14. These results are consistent with a recent report that the $\alpha 1$ glycine receptor subunit appears gradually in the rat LSO during development (Friauf et al., 1997).

Although BIC and SN are well established blockers of $\mathrm{GABA}_{\mathrm{A}}$ and glycine receptors, respectively, a certain degree of crossreactivity is possible. Trombley and Shepherd (1994) have shown that $30 \mu \mathrm{M}$ SN can antagonize GABA-evoked currents in the olfactory bulb, although 3-10 $\mu \mathrm{M}$ BIC had no effect on glycinemediated currents. It is unlikely that substantial cross-reactivity contributed to the present results because (1) there is a complementary decrease of IPSC amplitude when BIC or SN is applied separately to the same neuron; that is, the percent IPSC amplitude remaining after BIC exposure (glycinergic component) is equal to the percent IPSC amplitude antagonized by SN exposure; (2) sensitivity of the two LSO limbs to BIC or SN differs in the same slice; and (3) the concentrations of SN (2 $\mu \mathrm{M})$ and BIC $(10 \mu \mathrm{M})$ were within the limits that exhibit selective antagonism (Dichter, 1980; Trombley and Shepherd, 1994).

Early development of GABA-containing neurons has been found throughout the nervous system (Lauder et al., 1986), and transient expression of GABA in the spinal cord has been particularly well studied (Obata et al., 1978; Reitzel et al., 1979; Maderdrut et al., 1986; Ma et al., 1992; Mitchell and Redburn, 1996). For example, in the chick spinal cord, there is a decrease in GABA-positive neurons and a complementary increase in glycine-positive neurons during embryonic development (Berki et al., 1995), and it was suggested that neurons may change transmitter phenotype. Recent immunohistochemical staining for GABA in the MNTB and LSO of neonatal ferrets (Henkel and Brunso-Bechtold, 1998) and gerbils (S. Korada and I. R. Schwartz, unpublished observations) suggests that it is expressed in neonates.

If MNTB afferents change transmitter, then this may reflect a process of differentiation such as has been described in the sympathetic nervous system. The adrenergic or cholinergic identity of sympathetic terminals is regulated by the local environment, electrical activity, and the postsynaptic target (Walicke et al., 1977; Habecker and Landis, 1994; Guidry and Landis, 1995; Reissman et al., 1996). Furthermore, the co-release of neurotransmitters may be more common than suspected although difficult to verify when many afferent pathways are present (Johnson, 1994).

There are several reasons why we failed to detect IPSPs in current clamp after SN exposure in previous studies. At times, a very small postsynaptic potential did remain (Sanes and Hafidi, 1996), but we did not consider this to be a significant synaptic component. It is possible that a poor space clamp obscured these small remaining PSPs, perhaps because GABAergic IPSPs originate at distal dendrites. In other cases (Fig. 3, left), SN application revealed an underlying excitatory current that obscured the GABAergic IPSC. In the present study, the pipette solution used for voltage-clamp studies (e.g., Cs and QX-314) and the presence of ionotropic glutamate receptor antagonists, permitted full analysis of inhibitory synaptic events. In this regard it is interesting that the staining pattern for $\mathrm{GABA}_{\mathrm{A}}$ receptors indicates that they are primarily localized in the neuropile at $\mathrm{P} 4$ (Fig. $9 \mathrm{~A}$ ) and do not surround the LSO somata as is found for gephyrin at P14 (Fig. $9 D)$. Gephyrin appears to induce clustering of $\mathrm{GABA}_{\mathrm{A}}$ receptor 

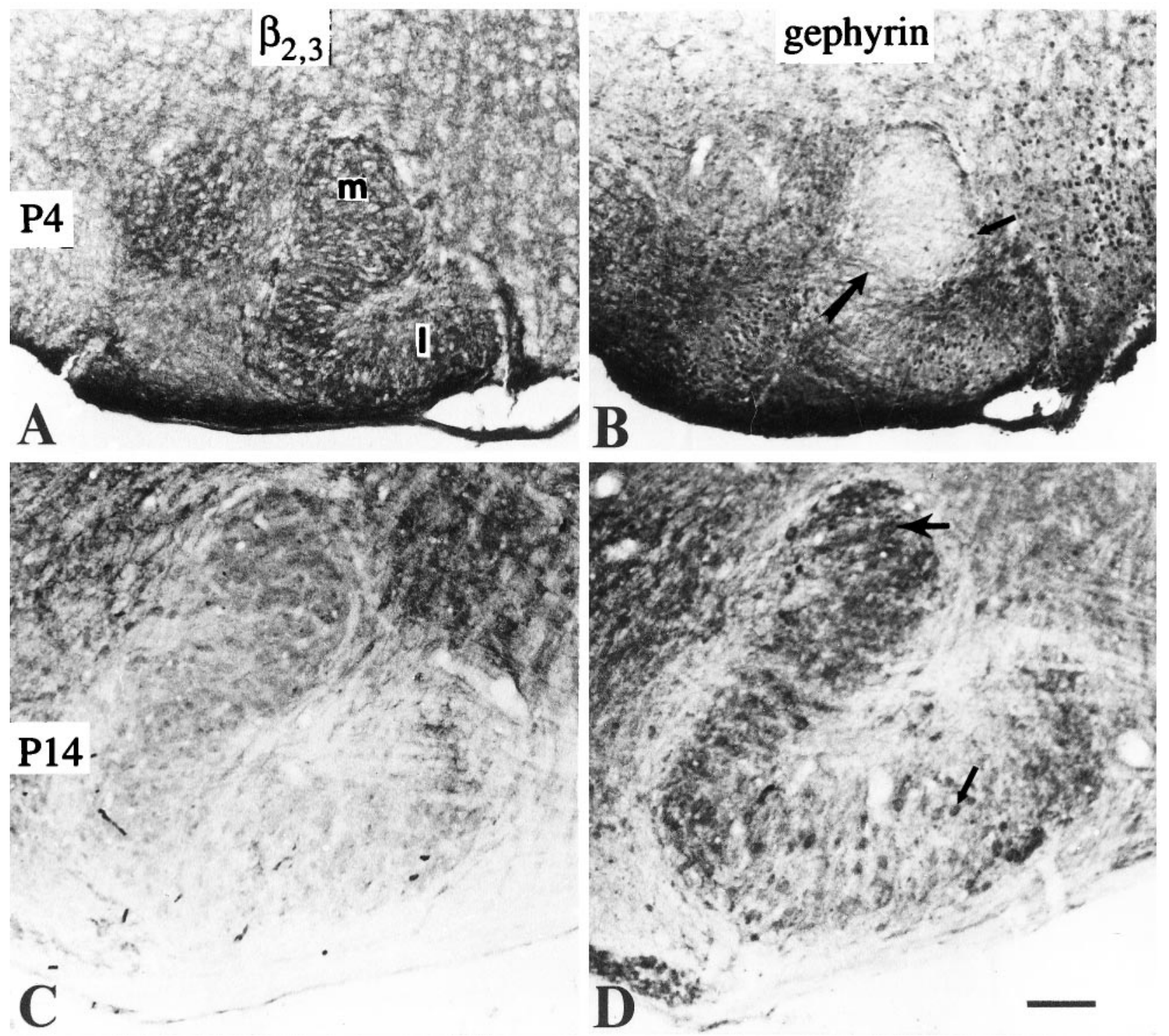

Figure 8. $A, \mathrm{GABA}_{\mathrm{A}}$ receptor staining $\left(\beta_{2,3}\right)$ at $\mathrm{P} 4$ shows similar intensity in both medial $(m)$ and lateral $(l)$ limbs of LSO. B, GlyR $($ gephyrin $)$ staining

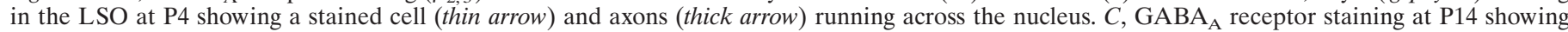
the decreased immunoreactivity in LSO compared with adjacent periolivary areas. $D$, GlyR immunoreactivity at P14 shows similar levels of intensity in the neurons of medial limb (thick arrow) and lateral limb (thin arrow). Note the intensely labeled neuropil in the medial limb. Scale bar, $100 \mu \mathrm{m}$.

subunits in the retina (Sassoè-Pogentto and Wässle, 1997). Thus, its absence from the medial limb at $\mathrm{P} 4$ suggests that the transiently expressed $\mathrm{GABA}_{\mathrm{A}}$ receptors may be uniformly distributed on the postsynaptic membrane.

\section{Implications for LSO function}

It is not clear how much GABAergic transmission remains in the adult gerbil LSO or what its role may be. GABA-evoked inhibition is present in $\sim 70 \%$ of adult chinchilla LSO neurons, although BIC only blocked contralateral auditory-evoked inhibition in 1 of 15 cells (Moore and Caspary, 1983). Ipsilateral inhibition has been described in vivo and in vitro (Brownell et al., 1979; Wu and Kelly, 1995), and contralateral excitation has been described for gerbil lateral limb neurons (Kil et al., 1995). However, the contralateral cochlear nucleus afferents did not apparently ar- borize within the medial limb from P3 onward (Kil et al., 1995). In P21-P45 mouse LSO neurons in vitro, BIC- or picrotoxinsensitive inhibitory transmission is observed, and contralaterally evoked excitatory responses are observed in the presence of strychnine (Wu and Kelly, 1995).

The medial and lateral limbs of the gerbil LSO exhibit several distinct anatomical properties. In the medial limb, neurons have more narrow dendritic arbors (Sanes et al., 1990), there is a greater density of $\left[{ }^{3} \mathrm{H}\right] \mathrm{SN}$ binding (Sanes et al., 1987), and there is a distinct complement of glial markers (Hafidi et al., 1994, 1996). The present data demonstrate two major differences in the development of inhibition in the lateral limb. First, there is no transition from GABAergic to glycinergic inhibition (Fig. 6), and the possibility that such a switch could have occurred in the lateral 

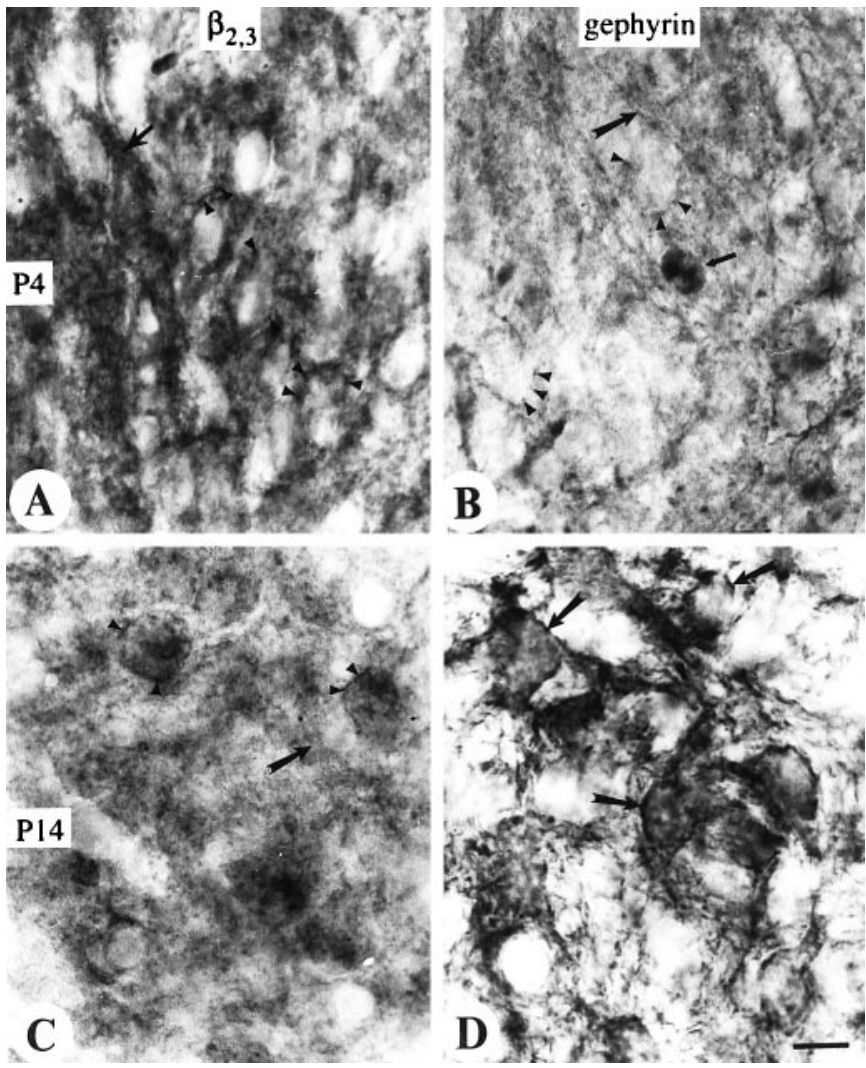

Figure 9. High-magnification pictures from the medial limb of LSO to show the $\mathrm{GABA}_{\mathrm{A}}$ receptor staining $\left(\beta_{2,3}\right)$ at $\mathrm{P} 4(A)$ and $\mathrm{P} 14(C)$ and glycine receptor staining (gephyrin) at P4 $(B)$ and P14 $(D)$. In $A-D$, medial is to the bottom, and lateral is to the top. $A$, Note the immunoreactive puncta on the somal surface (arrowheads) and intensely stained neuropil (arrows). B, Very lightly stained GlyR immunoreactive puncta (arrowheads) at $\mathrm{P} 4$ and also the same stained cell (thin arrow) as shown in Figure $8 B$. Note the stained axons (thick arrow). $C$, Decreased GABA $_{\mathrm{A}}$ receptor immunoreactive puncta (arrowheads) at P14 and diffusely labeled neuropil (arrow). D, GlyR-positive puncta on the neurons (arrows) show increased intensity at P14. Scale bar, $10 \mu \mathrm{m}$.

limb before P3 is also unlikely, because preliminary immunohistochemical observations in two P0 animals showed $\beta_{2,3}$ and gephyrin staining patterns similar to those observed at P4. Second, the IPSC reversal potential is mature from the earliest age examined. In medial limb neurons, $E_{\mathrm{IPSC}}$ gradually shifts toward the calculated $E_{\mathrm{Cl}}\left(\mathrm{Cl}_{\text {pipette }}=14 \mathrm{mM} ; \mathrm{Cl}_{\mathrm{ACSF}}=132 ; E_{\mathrm{Cl}}=-58\right.$ $\left.\log _{10}\left[\mathrm{Cl}_{\text {out }}\right] /\left[\mathrm{Cl}_{\text {in }}\right]=-58 \log _{10}[132 \mathrm{~mm}] /[14 \mathrm{mM}]=-56.6 \mathrm{mV}\right)$, whereas the $E_{\text {IPSC }}$ of lateral limb neurons was mature at P3. The shift of $E_{\text {IPSC }}$ toward $E_{\mathrm{C} 1}$ is consistent with depolarizing IPSPs in the neonatal rat LSO (Kandler and Friauf, 1995). Thus, the transport mechanism that establishes the chloride equilibrium potential (Rivera et al., 1997) may develop earlier in the lateral limb.

In the open field, low-frequency LSO neurons encounter minor level differences but may exhibit a sensitive response to time differences (Joris and Yin, 1990; Finlayson and Caspary, 1991). Therefore, inhibitory projections from the MNTB to the lateral limb may participate in temporal processing, as suggested by intracellular recordings from a brain slice preparation (Sanes, 1990). Although this discussion does not explain why inhibition in the lateral limb must develop in a different manner from the medial, it does suggest that lateral limb neurons may display a distinct pattern of differentiation, because their functional properties differ from those of medial limb neurons.

\section{Possible significance of GABAergic transmission}

A number of studies indicate that GABAergic transmission is an important signal during development. Results from in vitro experiments suggest that GABAergic signaling can modulate process outgrowth (Michler-Stuke and Wolff, 1987; Spoerri, 1988; Mattson and Kater, 1989; Behar et al., 1996), synaptogenesis (Corner and Ramakers, 1992; Redburn, 1992), and $\mathrm{GABA}_{\mathrm{A}}$ receptor expression (Frieder and Grimm, 1985; Hablitz et al., 1989; Montpied et al., 1991; Kim et al., 1993; Liu et al., 1997; Poulter et al., 1997). Thus, neonatal GABAergic transmission in the LSO may influence the transition to glycinergic transmission.

Our previous studies have shown that manipulations designed to decrease inhibitory transmission in the LSO have a major impact on the development of structure and function (Sanes and Chokshi, 1992; Sanes et al., 1992; Aponte et al., 1996; Sanes and Hafidi, 1996). Contralateral cochlear ablation and SN rearing cause a reduction in MNTB-evoked inhibition and an unexpected enhancement of ipsilaterally evoked excitation (Kotak and Sanes, 1996). Because one manipulation uses SN, we concluded that glycinergic inhibition plays an important role in neuronal maturation. Contralateral cochlear ablation, which functionally denervates the MNTB, should have affected GABAergic and glycinergic transmission, whereas $\mathrm{SN}$ rearing should attenuate glycinergic transmission only. The relative efficacy of each treatment is not known, and it is possible that contralateral ablation is less effective at attenuating glycinergic transmission than $\mathrm{SN}$ treatment.

One possibility is that glycinergic and GABAergic transmission exert a similar influence on the maturation of postsynaptic neurons. For example, GABA or glycine can depolarize neurons during early development and cause influx of calcium (Conner et al., 1987; Ben-Ari et al., 1989; Ito and Cherubini, 1991; Obrietan and Van den Pol, 1995; Boehm et al., 1997; Lo et al., 1998). In the rat, both inhibitory potentials and glycine are almost exclusively depolarizing before P7 (Kandler and Friauf, 1995).

It is also possible that GABA is released in neonates because it can activate a metabotropic pathway, a mechanism that is unknown for glycinergic systems. Activation of presynaptic $\mathrm{GABA}_{\mathrm{B}}$ receptors produced an extended depression of ipsilateral excitatory and MNTB-evoked inhibitory synaptic responses (Fig. 7). Presynaptic $\mathrm{GABA}_{\mathrm{B}}$ receptors inhibit transmission in neonatal rat hippocampus (Gaiarsa et al., 1995). The electrical properties of postsynaptic LSO neurons remained primarily unchanged after baclofen exposure, suggesting that ionotropic $\mathrm{GABA}_{\mathrm{B}}$ receptors are not significantly involved (Dutar and Nicoll, 1988). Rather, the prolonged time course of synaptic depression (10-15 min) indicates that metabotropic $\mathrm{GABA}_{\mathrm{B}}$ receptors may be located on afferent terminals (Bowery, 1989). Baclofen-sensitive $\mathrm{GABA}_{\mathrm{B}}$ mechanisms have been shown to modulate second messenger pathways (Tremblay et al., 1995; Barthel et al., 1995; Zhang et al., 1997). The GABAergic system appears to be one of several metabotropic pathways in the developing LSO, and we have previously described long-lasting effects of glutamate and serotonin (Kotak and Sanes, 1995; Fitzgerald and Sanes, 1997). Therefore, a comprehensive understanding of synaptogenesis and plasticity in the developing LSO may require an understanding of both the electrical and chemical changes that surround synaptic transmission. 


\section{REFERENCES}

Aponte JE, Kotak VC, Sanes DH (1996) Decreased synaptic inhibition leads to dendritic hypertrophy prior to the onset of hearing. Auditory Neurosci 2:235-240.

Barthel F, Campard PK, Demeneix BA, Feltz P, Loeffler JP (1995) $\mathrm{GABA}_{\mathrm{B}}$ receptors negatively regulate transcription in cerebellar granular neurons through cyclic AMP responsive element binding proteindependent mechanism. Neuroscience 70:417-427.

Behar TN, Li Y-X, Tran HT, Ma W, Dunlap V, Scott C, Barker JL (1996) GABA stimulates chemotaxis and chemokinesis of embryonic cortical neurons via calcium-dependent mechanisms. J Neurosci 16:1808-1818.

Ben-Ari Y, Cherubini E, Corradetti R, Gaiarsa JL (1989) Giant synaptic potentials in immature rat CA3 hippocampal neurones. J Physiol (Lond) 416:303-325.

Berki AC, O’Donovan MJ, Antal M (1995) Developmental expression of glycine immunoreactivity and its colocalization with GABA in the embryonic chick lumbosacral spinal cord. J Comp Neurol 362:583-596.

Boehm S, Harvey RJ, von Holst A, Rohrer H, Betz H (1997) Glycine receptors in cultured chick sympathetic neurons are excitatory and trigger neurotransmitter release. J Physiol (Lond) 504:683-694.

Bormann J, Hamill OP, Sakmann B (1987) Mechanism of anion permeation through channels gated by glycine and $\gamma$-aminobutyric acid in mouse cultured spinal neurones. J Physiol (Lond) 385:243-286.

Boudreau JC, Tsuchitani C (1970) Cat superior olive s-segment cell discharge to tonal stimulation. In: Contributions to sensory physiology, Vol. 4 (Neff WD, ed), pp 143-213. New York: Academic.

Bowery NG (1989) GABA $_{\mathrm{B}}$ receptors and their significance in mammalian pharmacology. Trends Pharmacol Sci 10:401-408.

Brownell WE, Manis PB, Ritz LA (1979) Ipsilateral inhibitory responses in the cat lateral superior olive. Brain Res 177:189-193.

Caird D, Klinke R (1983) Processing of binaural stimuli by cat superior olivary complex neurons. Exp Brain Res 52:385-399.

Cash S, Zucker RS, Poo M-M (1996) Spread of synaptic depression mediated by presynaptic cytoplasmic signaling. Science 272:998-1001.

Connold AL, Evers JV, Vrbová G (1986) Effect of low calcium and protease inhibitors on synapse elimination during postnatal development in the rat soleus muscle. Dev Brain Res 28:99-107.

Connor JA, Tseng HY, Hockberger PE (1987) Depolarization- and transmitter-induced changes in intracellular $\mathrm{Ca} 2+$ of rat cerebellar granule cells in explant cultures. J Neurosci 7:1384-1400.

Corner MA, Ramakers GJA (1992) Spontaneous firing as an epigenetic factor in brain: development-physiological consequences of chronic tetrodotoxin and picrotoxin exposure on cultured rat neocortex neurons. Dev Brain Res 65:57-64.

Dichter MA (1980) Physiological identification of GABA as the inhibitory transmitter for mammalian cortical neurons in cell culture. Brain Res 190:111-121.

Dutar P, Nicoll RA (1988) The physiological role of GABA $_{\mathrm{B}}$ receptors in the central nervous system. Nature 332:156-158.

Finlayson PG, Caspary DM (1991) Low-frequency neurons in the lateral superior olive exhibit phase-sensitive binaural inhibition. J Neurophysiol 65:598-605.

Fitzgerald KF, Sanes DH (1997) Serotonergic modulation in gerbil lateral superior olive: effects of 5-HT agonists. Soc Neurosci Abstr 23:1550.

Friauf E, Hammerschmidt B, Kirsch J (1997) Development of adult-type inhibitory glycine receptors in the central auditory system of rats. J Comp Neurol 385:117-134.

Frieder B, Grimm VE (1985) Some long-lasting neurochemical effects of prenatal or early postnatal exposure to diazepam. J Neurochem 45:37-42.

Fritschy J-M, Paysan J, Enna A, Mohler H (1994) Switch in the expression of rat $\mathrm{GABA}_{\mathrm{A}}$-receptor subtypes during postnatal development: an immunocytochemical study. J Neurosci 14:5302-5324.

Gaiarsa J-C, Tseeb B, Ben-Ari Y (1995) Postnatal development of preand postsynaptic GABAb-mediated inhibitions in the CA3 hippocampal region of the rat. J Neurophysiol 73:246-255.

Guidry G, Landis S (1995) Sympathetic axons pathfind successfully in the absence of target. J Neurosci 15:7565-7574.

Guinan Jr JJ, Guinan SS, Norris BE (1972a) Single auditory units in the superior olivary complex. I. Responses to sounds and classifications based on physiological properties. Int J Neurosci 4:101-120.
Guinan Jr JJ, Norris BE, Guinan SS (1972b) Single auditory units in the superior olivary complex. I. Locations of unit categories and tonotopic organization. Int J Neurosci 4:147-166.

Habecker BA, Landis SC (1994) Noradrenergic regulation of cholinergic differentiation. Science 264:1602-1604.

Hablitz JJ, Tehrani MH, Barnes Jr EM (1989) Chronic exposure of developing cortical neurons to GABA down-regulates GABA/benzodiazepine receptors and GABA-gated chloride currents. Brain Res 501:332-338.

Hafidi A, Sanes DH, Kedeshian P, Hillman DE (1994) Structural and molecular heterogeneity of astrocytes and oligodendrocytes in the gerbil lateral superior olive. Neuroscience 60:503-519.

Hafidi A, Katz JA, Sanes DH (1996) Differential expression of MAG, MBP and L1 in the developing lateral superior olive. Brain Res 736:35-43.

Harnischfeger G, Neuweiler G, Schlegel P (1985) Interaural time and intensity coding in superior olivary complex and inferior colliculus of the echo locating bat Molossus ater. J Neurophysiol 53:89-109.

Helfert RH, Bonneau JM, Wenthold RJ, Altschuler RA (1989) GABA and glycine immunoreactivity in the guinea pig superior olivary complex. Brain Res 501:269-286.

Helfert RH, Juiz JM, Bledsoe Jr SC, Bonneau JM, Wenthold RJ, Altschuler RA (1992) Patterns of glutamate, glycine and GABA immunolabeling in four synaptic terminal classes in the lateral superior olive of the guinea pig. J Comp Neurol 323:305-325.

Henkel CK, Brunso-Bechtold JK (1998) Calcium-binding proteins and GABA reveal spatial segregation of cell types within the developing lateral superior olivary nucleus of the ferret. Microsc Res Tech, in press.

Ito S, Cherubini E (1991) Strychnine-sensitive glycine responses of neonatal rat hippocampal neurones. J Physiol (Lond) 440:67-83.

Johnson MD (1994) Synaptic glutamate release by postnatal rat serotonergic neurons in microculture. Neuron 12:433-442.

Joris PX, Yin TCT (1990) Time sensitivity of cells in the lateral superior olive (LSO) to monaural and binaural amplitude modulated complexes. Assoc Res Otolaryngol Abstr 13:267.

Kandler K, Friauf E (1995) Development of glycinergic and glutamatergic synaptic transmission in the auditory brainstem of perinatal rats. J Neurosci 15:6890-6904.

Kil J, Lageyama G, Semple MN, Kitzes LM (1995) Development of ventral cochlear nucleus projections to the superior olivary complex in gerbil. J Comp Neurol 353:317-340.

Kim HY, Sapp DW, Olsen RW, Tobin AJ (1993) GABA alters GABA receptor mRNAs and increases ligand binding. $J$ Neurochem 61:2334-2337.

Kotak VC, Sanes DH (1995) Synaptically evoked prolonged depolarizations in the developing auditory system. J Neurophysiol 74:1611-1620.

Kotak VC, Sanes DH (1996) Developmental influence of glycinergic transmission: regulation of NMDA receptor-mediated EPSPS. J Neurosci 16:1836-1843.

Lauder JM, Han VK, Henderson P, Verdoorn T, Towle AC (1986) Prenatal ontogeny of the GABAergic system in the rat brain: an immunocytochemical study. Neuroscience 19:465-493.

Liu J, Morrow AL, Devaud LL, Grayson DR, Lauder JM (1997) Regulation of $\mathrm{GABA}_{\mathrm{A}}$ receptor subunit mRNA expression by the pesticide dieldrin in embryonic brainstem cultures: a quantitative, competitive reverse transcription-polymerase chain reaction study. J Neurosci Res 49:645-653.

Lo YJ, Rao SC, Sanes DH (1998) Modulation of calcium by inhibitory systems in the developing auditory system. Neuroscience 83:1075-1084.

Ma W, Behar T, Barker JL (1992) Transient expression of GABA immunoreactivity in the developing rat spinal cord. J Comp Neurol 325:271-290.

Maderdrut JL, Reitzel JL, Oppenheim RW (1986) Further behavioral analysis of GABA-mediated inhibition in the early chick embryo. Brain Res 390:157-160.

Mattson MP, Kater SB (1989) Excitatory and inhibitory neurotransmitters in the generation and degeneration of hippocampal neuroarchitecture. Brain Res 478:337-348.

Michler-Stuke A, Wolff JR (1987) Facilitation and inhibition of neuron elongation by GABA in chick tectal neurons. In: Neurotrophic activity of GABA during development. Neurology and neurobiology, Vol 32 (Redburn DA, Schousboe A, eds), pp 253-266. New York: Liss. 
Mitchell CK, Redburn DA (1996) GABA and $\mathrm{GABA}_{\mathrm{A}}$ receptors are maximally expressed in association with cone synaptogenesis in neonatal rabbit retina. Dev Brain Res 95:63-71.

Moore MJ, Caspary DM (1983) Strychnine blocks binaural inhibition in lateral superior olivary neurons. J Neurosci 3:237-247.

Montpied P, Ginns EI, Martin BM, Roca D, Farb DH, Paul SM (1991) $\gamma$-Aminobutyric acid (GABA) induces a receptor-mediated reduction in GABAA receptor alpha subunit messenger RNAs in embryonic chick neurons in culture. J Biol Chem 266:6011-6014.

Obata K, Oide M, Tanaka H (1978) Excitatory and inhibitory actions of GABA and glycine on embryonic chick spinal neurons in culture. Brain Res 144:179-184.

Obrietan K, Van den Pol AN (1995) GABA neurotransmission in the hypothalamus: developmental reversal from $\mathrm{Ca}^{2+}$ elevating to depressing. J Neurosci 15:5065-5077.

Poulter MO, Ohannesian L, Larmet Y, Feltz P (1997) Evidence that $\mathrm{GABA}_{\mathrm{A}}$ receptor subunit mRNA expression during development is regulated by $\mathrm{GABA}_{\mathrm{A}}$ receptor stimulation. J Neurochem 68:631-639.

Redburn DA (1992) Development of GABAergic neurons on the mammalian retina. In: Progress in brain research, Vol 90 (Mize RR, Marc RR, Sillito AM, eds), pp 133-147. New York: Elsevier.

Reissman E, Ernsberger U, Francis-West PH, Rueger D, Brickell PM, Rohrer H (1996) Involvement of bone morphogenetic protein-4 and bone morphogenetic protein-7 in the differentiation of the adrenergic phenotype in developing sympathetic neurons. Development 122:2079-2088.

Reitzel JL, Maderdrut JL, Oppenheim RW (1979) Behavioral and biochemical analysis of GABA-mediated inhibition in the early chick embryo. Brain Res 172:487-504.

Rivera C, Wegelius K, Reeben M, Saarma M, Kaila K (1997) Developmental regulation of $\mathrm{K}-\mathrm{Cl}$ cotransporter (KCC2 and KCC1) mRNA in early postnatal rat hippocampus. Soc Neurosci Abstr 23:44.

Sanes DH (1990) An in vitro analysis of sound localization mechanisms in the gerbil lateral superior olive. J Neurosci 10:3494-3506.

Sanes DH (1993) The development of synaptic function and integration in the central auditory system. J Neurosci 13:2627-2637.

Sanes DH, Chokshi P (1992) Glycinergic transmission influences the development of dendritic shape. NeuroReport 3:323-326.

Sanes DH, Hafidi A (1996) Glycinergic transmission regulates dendrite size in organotypic culture. J Neurobiol 31:503-511.

Sanes DH, Rubel EW (1988) The ontogeny of inhibition and excitation in the gerbil lateral superior olive. J Neurosci 8:682-700.

Sanes DH, Siverls V (1991) The development and specificity of inhibitory axonal arborizations in the lateral superior olive. J Neurobiol 22:837-854.
Sanes DH, Takács C (1993) Activity-dependent refinement of inhibitory connections. Eur J Neurosci 5:570-574.

Sanes DH, Geary WA, Wooten F, Rubel EW (1987) Quantitative distribution of the glycine receptor in the auditory brain stem of the gerbil. J Neurosci 7:3793-3802.

Sanes DH, Goldstein NA, Ostad M, Hillman DE (1990) Dendritic morphology of central auditory neurons correlates with their tonotopic position. J Comp Neurol 294:443-454.

Sanes DH, Markowitz, S, Bernstein J, Wardlow J (1992) The influence of inhibitory afferents on the development of postsynaptic dendritic arbors. J Comp Neurol 321:637-644.

Sassoè-Pognetto M, Wässle H (1997) Synaptogenesis in the rat retina: subcellular localization of glycine receptors, $\mathrm{GABA}_{\mathrm{A}}$ receptors and the anchoring protein gephyrin. J Comp Neurol 381:158-174.

Schwartz IL (1992) the superior olivary complex and lateral lemniscal nuclei. In: The mammalian auditory pathway: neuroanatomy (Webster DB, Popper AN, Fay RR, eds), pp. 117-167. New York: Springer.

Spangler KM, Warr WB, Henkel CK (1985) The projections of principal cells of the medial nucleus of the trapezoid body in the cat. J Comp Neurol 238:249-262.

Spoerri PE (1988) Neurotrophic effects of GABA in cultures of embryonic chick brain and retina. Synapse 2:11-22.

Tremblay E, Ben-Ari Y, Roisin MP (1995) Different GABA $_{B}$-mediated effects on protein kinase $\mathrm{C}$ activity and immunoreactivity in neonatal and adult rat hippocampal slices. J Neurochem 65:863-870.

Trombley PQ, Shepherd GM (1994) Glycine exerts potent inhibitory actions on mammalian olfactory bulb neurons. J Neurophysiol 71:761-767.

Walicke PA, Campenot RB, Patterson PH (1977) Determination of transmitter function by neuronal activity. Proc Natl Acad Sci USA 74:5767-5771.

Wenthold RJ, Huie D, Altschuler RA, Reeks KA (1987) Glycine immunoreactivity localized in the cochlear nucleus and superior olivary complex. Neuroscience 22:897-912.

Wenthold RJ, Altschuler RA, Hampson DR (1990) Immunocytochemistry of neurotransmitter receptors. J Electron Microsc Tech 15:81-96.

Wu SH, Kelly JB (1995) Inhibition in the superior olivary complex: pharmacological evidence from mouse brain slice. J Neurophysiol 73:256-269.

Zhang J, Shen W, Slaughter MM (1997) Two metabotropic $\gamma$-aminobutyric acid differentially modulate calcium currents in retinal ganglion cells. J Gen Physiol 110:45-58.

Zook JM, DiCaprio RA (1988) Intracellular labeling of afferents to the lateral superior olive in the bat, Eptesicus fuscus. Hear Res 34:141-148. 